\title{
Stereochemistry of Nucleophilic Reductions of 2-Methyl-4-t-butyl- cyclohexanones. Further Support for the Linear Combination of SSC and PSC Stereochemical Models
}

\author{
Jim-Min Fang, ${ }^{a}$ Shih-Feng Sun, ${ }^{b}$ and Min-Hon Rei ${ }^{b}$ \\ a Department of Chemistry, and ${ }^{b}$ Department of Chemical Engineering, National Taiwan University, Taipei, \\ Taiwan 10764, Republic of China
}

trans-2-Methyl-4-t-butylcyclohexanone reacts with lithium aluminum hydride, lithium trimethoxyaluminium hydride and methyl-lithium with equal stereoselectivity of axial attack (i.e. $95 \pm 1 \%$ ). This is attributed to the equal steric strain control (SSC) of these three reagents in the absence of product stability control (PSC) brought about by the equal stability of its two secondary alcohol products (i.e. $\Delta G^{\circ}=0$ and $\left.\Delta \pi=a \Delta G^{\circ}=0\right)$.

Also presented for comparison are the stereochemistries of the reactions of 4-t-butylcyclohexanone, 2-methylcyclohexanone, cis-2-methyl-4-t-butylcyclohexanone and 2,2- dimethyl-4-t-butylcyclohexanone. In these three systems, the stereochemical courses of addition are controlled by $\operatorname{SSC}(\Delta \delta)$ and $\operatorname{PSC}(\Delta \pi)$ simultaneously, i.e. $\Delta\left(\Delta G^{\ddagger}\right)=\Delta \delta+\Delta \pi$.

Numerous proposals have been advanced to rationalize the preferential formation of equatorial alcohols from reduction by various metal hydrides of simple cyclohexanone derivatives. ${ }^{1-5}$ Thus, according to Cherest and Felkin, ${ }^{1}$ the formation of equatorial alcohol from axial attack of nucleophile is preferred in order to avoid torsional strain between the nucleophile and the two equatorial C-H bonds at C-2 and C-6. Likewise, $\mathrm{Anh}^{2}$ emphasizes the greater stability of the axial transition state by the $\delta^{*}$ antibonding interaction with the two axial $\mathrm{C}-\mathrm{H}$ bonds at C-2 and C-6. Cieplak, on the other hand, proposes an alternative model to account for the lower energetic barrier of the axial transition state which leads to the preferential formation of equatorial alcohol. ${ }^{3}$ According to Cieplak's model, the stereochemistry of the nucleophilic reduction $\dagger$ is primarily determined in the bond-forming process and the axial transition state leading to formation of equatorial $\mathrm{OH}$ is more stable because of interaction with the neighbouring occupied orbitals.

Although rapid advancement in computer technology makes MO calculation more convenient, ${ }^{3,4}$ lack of a precise characterization of the transition-state complex still hampers the practical usage of this approach for a quantitative assertion of the stereochemistry of the nucleophilic reduction of cyclic ketones.

Following our earlier postulations that stereochemical courses of nucleophilic reduction of ketones are determined by two competing factors, steric strain control (SSC) and product stability control (PSC), ${ }^{6,7}$ we have proposed that the actual transition-state complex is neither purely reactant-like nor purely product-like but is between these two extremes. In the past five years, we have advanced a linear combination of SSC and PSC models for the rationalization and prediction of the stereochemical courses of nucleophilic reductions of various cyclic ketones including open and crowded cyclopentanone, cyclohexanone and norbornanone derivatives. ${ }^{8}$

According to this model, the energy difference between two epimeric transition states, $\Delta\left(\Delta G^{\ddagger}\right)$, can be calculated from the magnitudes of SSC and PSC making the following assumptions.

$\dagger$ Throughout this paper 'nucleophilic reduction or addition' will be used to represent the formation of alcohol product from reduction of ketone by lithium aluminium hydride, or lithium trimethoxyaluminium hydride or by the addition of methyl-lithium. (a) The transition-state complex can be visualized as being composed of two hypothetical extremes, reactant-like and product-like, with the energy difference $\Delta\left(\Delta G^{\ddagger}\right)$ equal to $\Delta \delta+$ $\Delta \pi$. (b) The energy difference of the two epimeric product-like transition-state complexes can be estimated from $\Delta \pi=a \Delta G^{\circ}$ where $\Delta G^{\circ}$ is the thermodynamic difference of product stabilities and $a$ is a constant related to the reducing agent. (c) $\Delta \delta$, The energy difference in SSC, would roughly equal $\Delta\left(\Delta G^{\ddagger}\right)$ in the reaction of methyl-lithium with the ketone, since the two epimeric product-like transition-state complexes are to have equal stability ( $\Delta \pi=0$ ) presuming the size of $O$-metal group is similar to that of methyl group. (d) Common reducing reagents such as lithium aluminium hydride (LAH) in THF solution, lithium trimethoxyaluminium hydride (LTMAH) in THF and methyl lithium (MeLi) in ether are equally stereospecific when only the reactant-like transition states are considered, i.e. $\Delta \delta_{\mathrm{LAH}}=\Delta \delta_{\mathrm{LTMAH}}=\Delta \delta_{\mathrm{MeLi}}$. The third assumption is justified in view of the observations that many methyl carbinols in cyclopentyl, cyclohexyl, bicyclo[2.2.1] heptyl, and bicyclo[3.3.1]nonyl systems show only small differences in stability in equilibration experiments with acid. ${ }^{9}$ The fourth assumption is made from comparisons of the stereospecificity of reduction of two ketones of roughly equal magnitudes of $\Delta \pi{ }^{8 a}$

Of the thirteen cyclic ketones we have successfully determined that, ${ }^{8 a, b}$ the two controlling factors $\Delta \delta$ and $\Delta \pi$ always act simultaneously on the stereochemical course of hydride reductions (LAH and LTMAH). In all of these systems, $\Delta \delta$ and $\Delta G^{\circ}{ }_{\mathbf{H}} \neq 0$; clear-cut tests for the above assumptions, particularly the last two, are not possible. However, in the current system, the nucleophilic reduction of trans-2-methyl-4-t-butylcyclohexanone, trans-(3), possesses a unique property in which the two alcoholic products have equal stabilities, $\Delta G^{\circ}=0$, according to Sicher and Tichy. ${ }^{10}$ Where $\Delta G^{\circ}=0$, the effect of PSC can, therefore, be neglected for reactions with $\mathbf{L A H}$, LTMAH, and MeLi. In other words, trans-(3) will react with LAH, LTMAH, and MeLi with equal stereospecificity under the control of sole factor, $\Delta \delta$. Consequently, the above assumptions can be checked with this system. In this paper the stereochemistries of nucleophilic reductions of trans-(3) are given and compared with those of 4-t-butylcyclohexanone, (1), 2-methylcyclohexanone, (2), cis-2-methyl-4-t-butylcyclohexanone, cis-(3), and 2,2-dimethyl-4-t-butylcyclohexanone (4). 


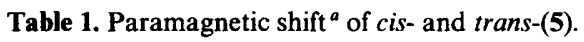

\begin{tabular}{|c|c|c|c|c|c|c|c|c|}
\hline \multirow{3}{*}{$\begin{array}{l}\mathrm{Eu}(\mathrm{fod})_{3} / \mathrm{ROH} \\
(\mathrm{mol} \%)\end{array}$} & \multicolumn{4}{|c|}{$c i s-(5)$} & \multicolumn{4}{|c|}{ trans-(5) } \\
\hline & \multicolumn{2}{|c|}{ 4-CMe } & \multicolumn{2}{|c|}{ 2-Me } & \multicolumn{2}{|c|}{ 4-CMe ${ }_{3}$} & \multicolumn{2}{|c|}{ 2-Me } \\
\hline & $\delta$ & $\Delta \delta$ & $\delta$ & $\Delta \delta$ & $\delta$ & $\Delta \delta$ & $\delta$ & $\Delta \delta$ \\
\hline 0 & 0.83 & 0 & 0.94 & 0 & 0.80 & 0 & 0.90 & 0 \\
\hline 0.86 & 0.90 & 0.07 & 1.05 & 0.11 & 0.86 & 0.06 & 1.12 & 0.22 \\
\hline 1.82 & 1.13 & 0.30 & 1.42 & 0.48 & 0.89 & 0.09 & 1.30 & 0.40 \\
\hline 2.90 & 1.31 & 0.48 & 1.71 & 0.77 & 0.95 & 0.15 & 1.70 & 0.80 \\
\hline 4.10 & 1.62 & 0.79 & 2.26 & 1.32 & 1.07 & 0.27 & 2.27 & 1.37 \\
\hline 7.02 & 1.97 & 1.14 & 2.78 & 1.84 & 1.18 & 0.38 & 3.03 & 2.13 \\
\hline$S^{b} / \mathrm{ppm}$ & & & & & & & & \\
\hline
\end{tabular}

${ }^{a}$ Varian EM-390 (90 MHz) in $\mathrm{CDCl}_{3} \cdot{ }^{b}$ Paramagnetic shift value $S$ is defined as $\Delta(\Delta \delta) /\left[\mathrm{Eu}(\mathrm{fod})_{3} / \mathrm{ROH}\right]$ by plotting $\Delta \delta$ against Eu(fod) $)_{3} / \mathrm{ROH}$. The values listed above are obtained from least-square plots using the package obtained from StatWorks of Heyden \& Son, Inc.

\section{Results and Discussion}

Preparation of trans-(3) via the $N, N$-dimethylhydrazone of (1) was undertaken; ${ }^{11-13}$ hydrolysis of the methylated hydrazone with $\mathrm{CuCl}_{2}$ or $\mathrm{NaIO}_{4}$ under buffered neutral conditions brought about an $81 \%$ yield of cis- and trans-(3) $(35: 65)$. Although the methylation reaction appeared to be stereospecific from the trans-side of the ring according to the ${ }^{1} \mathrm{H}$ n.m.r. analysis, partial epimerization could have occurred during hydrolysis and work-up. Nevertheless, separation of the mixture with h.p.l.c. yielded highly pure trans-(3) (over $99 \%$ ) in a respectable quantity. Structural determinations of cis- and trans-(3) were performed mainly by the use of ${ }^{1} \mathbf{H}$ n.m.r. spectroscopy. Compound cis-(3) exhibited a resonance due to the C-2 methyl group at $\gamma 0.97(\mathrm{~d}, J 6.5 \mathrm{~Hz}$ ) while trans-(3) showed the corresponding resonance at $\delta 1.12(\mathrm{~d}$, $J 7.0 \mathrm{~Hz}){ }^{14-16}$
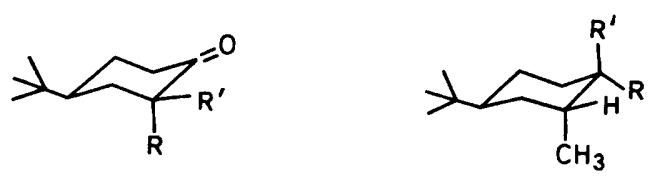

$$
\begin{array}{rr}
(1) R^{\prime}=R=H & \text { cis }-(5) R=H, R^{\prime}=O H \\
(2) R^{\prime}=C_{3}, R=H & \text { trans }-(5) R=O H, R^{\prime}=H \\
\text { (Without } \left.4-B u^{t}\right) & \\
\text { cis }-(3) R^{\prime}=C_{3}, R=H & \text { cis }-(6) R=C H_{3}, R^{\prime}=O H \\
\text { trans }-(3) R^{\prime}=H, R=C_{3} & \text { trans }-(6) R=O H, R^{\prime}=C_{3} \\
(4) R^{\prime} & =R=C_{3}
\end{array}
$$

The two secondary alcohols, cis-(5) (5\%) and trans-(5) (95\%) from LAH reduction of trans-(3) were characterized by ${ }^{1} \mathrm{H}$ n.m.r. spectroscopy including the use of paramagnetic-shift reagent, $\mathrm{Eu}(\mathrm{fod})_{3}$. Compound cis-(5) is a colourless crystal with m.p. $70-71^{\circ} \mathrm{C}$ (lit., ${ }^{17} 70-71^{\circ} \mathrm{C}$ ) identical with the value reported for trans-2-methyl-cis-4-t-butylcyclohexanol. The other compound, trans-(5) having m.p. $64-65^{\circ} \mathrm{C}$ (lit., ${ }^{17} 60-62^{\circ} \mathrm{C}$ ) was assigned as cis-2-methyl-trans-4-t-butylcyclohexanol; this is in agreement with the larger $S$-value for 2-Me and smaller $S$-value for $4-\mathrm{CMe}_{3}$ by the paramagnetic shift of an equatorial $\mathrm{OH}$ group (Table 1). ${ }^{18}$

Previously, two tertiary-alcohol products in 20 and $80 \%$ distribution have been obtained from the reaction of trans-(3) and MeMgI in ether by Ficini and Maujean; ${ }^{19}$ based on chemical shifts of $\mathrm{OH}$ groups (3.90 versus 3.75 p.p.m. in $\mathrm{Me}_{2} \mathrm{SO}$ ), they assigned the major component, m.p. $67.5^{\circ} \mathrm{C}$, and the minor component, liquid, to equatorial and axial alcohols, respectively. In our tertiary alcohol products, the major one [trans- $(6), 96 \%$ from $\mathrm{MeLi}$ at $\left.0{ }^{\circ} \mathrm{C}\right]$, m.p. $69-70^{\circ} \mathrm{C}$, is, therefore, assigned as 1-methyl-cis-2-methyl-trans-4-t-butylcyclohexanol; the minor component [cis-(6), 4\%], liquid, is 1-methyl-trans-2methyl-cis-4-t-butylcyclohexanol with compatible ${ }^{1} \mathrm{H}$ n.m.r. spectra (Table 2).

\section{Stereochemistry}

The stereochemistries of nucleophilic additions of (1) and (2) have been attributed to a linear combination of SSC $(\Delta \delta)$ and PSC $(\Delta \pi)$ in the previous study. ${ }^{8 a, c}$ In these cases, $\Delta \delta$ and $\Delta \pi$ are different in sign with the absolute values of $\Delta \pi$ being larger than those of $\Delta \delta$; thus, the net result is the dominance of the $\Delta \pi$ effect (PSC) on the stereochemical course of these reactions. With (4), the stereochemistries of LAH and LTMAH are highly stereoselective due to a combined effect of both $\Delta \delta$ and $\Delta \pi$ in the same direction. ${ }^{8 b, c}$

Earlier we assumed that LAH, LTMAH, and MeLi have $c a$. equal steric strain controlling effect (i.e. $\Delta \delta_{\mathrm{H}}=\Delta \delta_{\mathrm{H}^{\prime}}=\Delta \delta_{\mathrm{Me}}$ ), and predicted that if $\Delta G^{\circ}$ was zero (hence, $\Delta \pi=0$ ), trans-(3) would react in equal stereoselectivity with these three reagents. This is indeed borne out by our latest experimental results shown in Table 3. All these three reagents react with trans-(3) by axial attack to give $95 \pm 1 \%$ of equatorial alcohol products trans-(5) and -(6). This is now readily understandable because of the absence of PSC effect (i.e., $\Delta \pi=0$ ). Under such conditions $(\Delta \pi=0)$, our previous assumption that LAH, LTMAH, and MeLi have equal steric-strain-controlling effects (i.e., $\Delta \delta_{\mathbf{H}}=$ $\left.\Delta \delta_{\mathrm{H}^{\prime}}=\Delta \delta_{\mathrm{Me}}\right)$ and $\Delta\left(\Delta G^{\ddagger}\right)_{\mathrm{Me}}=\Delta \delta_{\mathrm{Me}}$ is now experimentally supported.

In the case of cis-(3), the stereochemical results are similar to those of (2) which is conformationally more labile. Moreover, applying $\Delta G^{\circ}=\Delta \pi / a(a=1.4$ for $\mathrm{LAH}$ and 0.4 for LTMAH), ${ }^{8 a, c}$ we are able to estimate that $\Delta G^{\circ}=1.2 \mathrm{kcal} \mathrm{mol}^{-1}$ for the two epimeric secondary alcohols, the equilibration of which was reported to be complex and was estimated to have $\Delta G^{\circ}=1.2 \mathrm{kcal} \mathrm{mol}^{-1}$ from chromic acid oxidation data. ${ }^{10}$ The slightly larger value of $\Delta G^{\circ}=1.2$ for cis-(3) than $1.15 \mathrm{kcal} \mathrm{mol}^{-1}$ for (2) can be attributed to the effect of the 4-Bu group stabilizing the conformation of cis-(3).

Comparison of $\Delta \delta$ values in the three sterically homogeneous ketones, cis- and trans-(3) and (4), we are surprised to find that these $\Delta \delta$ values are linearly additive within the experimental deviations; $\Delta \delta[$ cis-(3) $]+\Delta \delta[$ trans-(3) $]=-0.9+$ $1.6=\Delta \delta(4)=0.7 \mathrm{kcal} \mathrm{mol}^{-1}$. The generality of this trend remains to be determined.

Stereoselectivity of LAH reductions $\left[\Delta\left(\Delta G^{\ddagger}\right)_{\mathrm{LAH}}\right]$ increases 


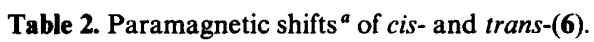

\begin{tabular}{|c|c|c|c|c|c|c|}
\hline \multirow{3}{*}{$\begin{array}{c}\mathrm{Eu}(\mathrm{fod})_{3} / \mathrm{ROH} \\
(\mathrm{mol} \%)\end{array}$} & \multicolumn{6}{|c|}{ cis-(6) } \\
\hline & \multicolumn{2}{|c|}{ 4- $\mathrm{CMe}_{3}$} & \multicolumn{2}{|c|}{$2-\mathrm{Me}$} & \multicolumn{2}{|c|}{$1-\mathrm{Me}$} \\
\hline & $\delta$ & $\Delta \delta$ & $\delta$ & $\Delta \delta$ & $\delta$ & $\Delta \delta$ \\
\hline 0 & 0.85 & 0 & 0.95 & 0 & 1.14 & 0 \\
\hline 0.86 & 0.85 & 0 & 0.97 & 0.02 & 1.19 & 0.05 \\
\hline 1.82 & 0.87 & 0.02 & 1.01 & 0.06 & 1.29 & 0.15 \\
\hline 2.90 & 0.88 & 0.04 & 1.06 & 0.11 & 1.42 & 0.28 \\
\hline 4.10 & 0.92 & 0.07 & 1.16 & 0.21 & 1.66 & 0.52 \\
\hline 7.02 & 0.96 & 0.11 & 1.29 & 0.34 & 1.98 & 0.84 \\
\hline$S^{b} / \mathrm{ppm}$ & & & & & & \\
\hline
\end{tabular}

\begin{tabular}{|c|c|c|c|c|c|}
\hline \multicolumn{6}{|c|}{ trans $-(6)$} \\
\hline \multicolumn{2}{|c|}{ 4- $\mathrm{CMe}_{3}$} & \multicolumn{2}{|c|}{ 2-Me } & \multicolumn{2}{|c|}{$1-\mathrm{Me}$} \\
\hline$\delta$ & $\Delta \delta$ & $\delta$ & $\Delta \delta$ & $\delta$ & $\Delta \delta$ \\
\hline 0.84 & 0 & 1.02 & 0 & 1.28 & 0 \\
\hline 0.84 & 0 & 1.03 & 0.01 & 1.28 & 0 \\
\hline 0.85 & 0.01 & 1.12 & 0.10 & 1.39 & 0.11 \\
\hline 0.88 & 0.04 & 1.23 & 0.21 & 1.51 & 0.23 \\
\hline 0.91 & 0.07 & 1.36 & 0.34 & 1.67 & 0.38 \\
\hline 0.95 & 0.11 & 1.62 & 0.60 & 1.99 & 0.71 \\
\hline & & & & & \\
\hline
\end{tabular}

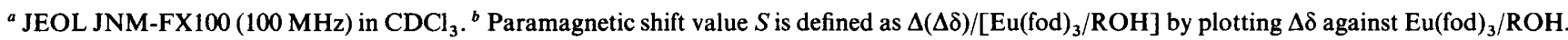
The values listed above are obtained from least-square plots using the package obtained from StatWorks of Heyden \& Son, Inc.

Table 3. Stereochemistry of the reactions of cyclohexanones with LAH, LTMAH, and MeLi at $0^{\circ} \mathrm{C}$.

\begin{tabular}{|c|c|c|c|c|c|c|c|c|c|c|}
\hline \multirow[b]{2}{*}{ Ketones } & \multicolumn{3}{|c|}{ trans-ROH ${ }^{a, b}(\mathrm{~mol} \%)$} & \multicolumn{3}{|c|}{$\Delta\left(\Delta G^{\ddagger}\right) / \mathrm{kcal} \mathrm{mol}^{-1}$} & \multirow[b]{2}{*}{$\Delta G^{\circ b} / \mathrm{kcal} \mathrm{mol}^{-1}$} & \multirow[b]{2}{*}{$\Delta \delta / \mathrm{kcal} \mathrm{mol}^{-1}$} & \multicolumn{2}{|c|}{$\Delta \pi^{b} / \mathrm{kcal} \mathrm{mol}^{-1}$} \\
\hline & LAH & LTMAH & $\mathrm{MeLi}$ & LAH & LTMAH & MeLi & & & LAH & LTMAH \\
\hline (1) & 89 & 58 & 35 & 1.1 & 0.2 & -0.3 & 0.9 & -0.3 & 1.45 & 0.5 \\
\hline (2) & 75 & 31 & 16 & 0.6 & -0.4 & -0.9 & 1.15 & -0.9 & 1.5 & 0.5 \\
\hline $\operatorname{cis-(3)}$ & 81 & 32 & 16 & 0.8 & -0.4 & -0.9 & $1.2^{c}$ & -0.9 & 1.7 & 0.5 \\
\hline trans-(3) & 95 & 94 & 96 & 1.6 & 1.5 & 1.7 & 0 & $1.6+0.1$ & 0 & 0 \\
\hline (4) & 96 & 80 & 78 & 1.7 & 0.75 & 0.7 & $0.58^{d}$ & 0.7 & 1.0 & 0.1 \\
\hline
\end{tabular}

a The 4-t-butyl group in the equatorial position is used as a reference group; therefore, trans- $\mathrm{ROH}$ has an equatorial OH group. ${ }^{b} \mathrm{Data}$ are taken from ref. $8(c)$, except those for cis-(3) and trans-(3). ${ }^{c}$ Calculated from average of $1.21 \mathrm{kcal} \mathrm{mol}^{-1}$ of $\Delta G_{\mathrm{H}}=\Delta \pi_{\mathrm{LAH}} / 1.4$ and of $1.23 \mathrm{kcal} \mathrm{mol} \mathrm{mol}^{-1}$ of $\Delta G_{\mathrm{H}}=\Delta \pi_{\mathrm{LTMAH}} / 0.4{ }^{d}$ Average of two literature values, 0.87 (J. Sicher and J. Zavada, Collect. Czech. Chem. Commun., 1967, 32, 2122) and 0.28 kcal $\mathrm{mol}^{-1}$ (J.-C. Richer and G. Perrault, Can. J. Chem., 1965, 43, 18).

from (1, (2), cis-(3) to trans-(3) and (4); this trend cannot be readily explained by the torsional-strain control. ${ }^{1}$ Similarly, torsional-strain control also fails to provide a consistent explanation for the observed stereochemical changes of these ketones in reactions with LTMAH or MeLi.

A shift of transition state co-ordinate from a product-like one to a reactant-like one in this series is unlikely because of the preservation of structural homogeneity of the carbonyl group in these ketones and the use of identical reaction conditions. Were this the case, similar increases in stereoselectivities should also be observed in their reactions with LTMAH and with MeLi. Likewise, these two rationalizations give unsatisfactory explanations for the observed variation in the stereochemical courses of LAH, LTMAH, and MeLi reactions with trans-(3) or (4).

With the linear combination of the SSC and PSC models, the observed change in stereoselectivity can be readily attributed to the varying degree of contributions of $\operatorname{SSC}(\Delta \delta)$ and PSC $(\Delta \pi)$ including the case for $\Delta \pi=0$ in trans-(3) and the reactions of $\mathrm{MeLi}$ with various ketones. Not only does this model provide a satisfactory explanation, qualitative as well as quantitative, for these cyclohexyl system, it also offers a universal rationalization for the observed stereochemistries in cyclopentyl and bicyclic systems for all the three reducing reagents. ${ }^{8}$

In conclusion, the data obtained from trans-(3) strongly support the steric strain controlling effect $(\Delta \delta)$ of LAH, LTMAH, and MeLi can be viewed as equal in magnitude and that $\Delta\left(\Delta G^{\ddagger}\right)_{\mathrm{Me}}=\Delta \delta$ is a valid assumption. Finally, the observed variation in the stereoselectivities of the reductions of cyclic ketones are best treated qualitatively and quantitatively with $\Delta\left(\Delta G^{\ddagger}\right)_{\mathrm{H}}=\Delta\left(\Delta G^{\ddagger}\right)_{\mathrm{Me}}+a \Delta G_{\mathrm{H}}^{\circ}(a=1.4$ for LAH and 0.4 for LTMAH).

\section{Experimental}

Preparation of trans-2-Methyl-4-t-butylcyclohexanone, trans(3).-A solution of lithium di-isopropylamide (LDA) $(0.33 \mathrm{~mol}$ $\mathrm{dm}^{-3}$ ) was prepared under a nitrogen atmosphere by the addition of $\mathrm{BuLi}$ [ $60 \mathrm{mmol}, 1.6 \mathrm{~mol} \mathrm{dm}^{-3}$ in hexane (Merck)], to a solution of di-isopropylamine $(65 \mathrm{mmol})$ in dry THF (140 $\mathrm{cm}^{3}$ ) at $0^{\circ} \mathrm{C}$. A solution of the $N, N$-dimethylhydrazone of (1) $(50 \mathrm{mmol})$ was added dropwise to the LDA solution. After being stirred for $3 \mathrm{~h}$ at $0^{\circ} \mathrm{C}$, the resulting yellow solution was cooled to $-78^{\circ} \mathrm{C}$, iodomethane $(65 \mathrm{mmol})$ was added and then the mixture was warmed to room temperature and stirred overnight. The volatiles were removed under reduced pressure, the residue was taken up in ether, and washed successively with aqueous sodium thiosulphate and brine. After being dried $\left(\mathrm{Na}_{2} \mathrm{SO}_{4}\right)$, the organic phase was concentrated to give a crude product ( $7.9 \mathrm{~g}$ ) of the $N, N$-dimethylhydrazone of trans-2methyl-4-t-butylcyclohexanone. ${ }^{13}$

The crude oil was treated with a solution of copper(II) chloride $(110 \mathrm{mmol})$ in a mixture of THF $\left(180 \mathrm{~cm}^{3}\right)$ and water $\left(90 \mathrm{~cm}^{3}\right)$ at $0{ }^{\circ} \mathrm{C}$ for $4 \mathrm{~h}$. After removal of volatiles, the residue was extracted twice with ether. The combined extracts were washed with brine, dried $\left(\mathrm{Na}_{2} \mathrm{SO}_{4}\right)$, filtered and concentrated under reduced pressure. After distillation $\left(52^{\circ} \mathrm{C} / 0.4 \mathrm{mmHg}\right), 2$ methyl-4-t-butylcyclohexanone $(41 \mathrm{mmol})$ was obtained as a mixture of trans-and cis-isomers (65:35). Separation of the two isomers was performed by h.p.l.c. [0.78 $\times 25 \mathrm{~cm} \mu$-Porasil column with EtOAc-hexane $(7: 93 \mathrm{v} / \mathrm{v}) ; 5.2 \mathrm{~cm}^{3} \mathrm{~min}^{-1}$ ]: cis$(3),{ }^{16} t_{\mathrm{R}}=3.60 \mathrm{~min}, \delta_{\mathrm{H}}\left(\mathrm{CDCl}_{3}\right) 0.90\left(9 \mathrm{H}, \mathrm{s}, \mathrm{CMe}_{3}\right), 0.97(3 \mathrm{H}$, $\mathrm{d}, J 6.5 \mathrm{~Hz}, 2-\mathrm{Me}), 1.35-1.75(5 \mathrm{H}, \mathrm{m})$, and $1.90-2.46(3 \mathrm{H}, \mathrm{m})$; trans- $(3),{ }^{16} t_{\mathrm{R}}=4.24 \mathrm{~min}, \delta_{\mathrm{H}}\left(\mathrm{CDCl}_{3}\right) 0.90\left(9 \mathrm{H}, \mathrm{s}, \mathrm{CMe}_{3}\right), 1.12$ $(3 \mathrm{H}, \mathrm{d}, J 7.0 \mathrm{~Hz}, 2-\mathrm{Me}), 1.40-2.80(5 \mathrm{H}, \mathrm{m})$, and $2.24-2.60(3 \mathrm{H}$, $\mathrm{m})$. 
Reduction of trans-2-Methyl-4-t-butylcyclohexanone with $L A H$. - To a cold suspension of LAH $\left(5 \mathrm{mmol}\right.$ in $30 \mathrm{~cm}^{3}$ of THF) was added dropwise a solution of trans-(3) $(10 \mathrm{mmol}$ in 5 $\mathrm{cm}^{3} \mathrm{THF}$ ) at $0^{\circ} \mathrm{C}$. After being stirred for $1 \mathrm{~h}$, the mixture was quenched with saturated ammonium chloride. The mixture was filtered and rinsed with ethyl acetate. Removal of the solvent afforded the alcoholic products, cis- and trans-(5) (5:95) (9.5 $\mathrm{mmol})$. The two epimers were separated by h.p.l.c. [eluant: EtOAc-hexane $(1: 9 \mathrm{v} / \mathrm{v})]$ : cis-(5), $t_{\mathrm{R}}=7.53 \mathrm{~min}$, colourless crystals, m.p. $70-71{ }^{\circ} \mathrm{C}$ (lit.., $\left.{ }^{17} 70-71{ }^{\circ} \mathrm{C}\right), \delta_{\mathrm{H}}\left(\mathrm{CDCl}_{3}\right) 0.83(9 \mathrm{H}, \mathrm{s}$, $\left.\mathrm{CMe}_{3}\right), 0.94(3 \mathrm{H}, \mathrm{d}, J 7.0 \mathrm{~Hz}, 2-\mathrm{Me}), 1.05-1.85(8 \mathrm{H}, \mathrm{m})$, and 3.55-3.72 $\left(1 \mathrm{H}, w_{1 / 2} 6 \mathrm{~Hz}\right)$; trans $-(5), t_{\mathrm{R}}=8.63 \mathrm{~min}$, colourless crystals, m.p. $64-65^{\circ} \mathrm{C}$ (lit. $\left.{ }^{17}{ }^{17} 60-62^{\circ} \mathrm{C}\right), \delta_{\mathrm{H}}\left(\mathrm{CDCl}_{3}\right) 0.80(9 \mathrm{H}, \mathrm{s}$, $\left.\mathrm{CMe}_{3}\right), 0.90(3 \mathrm{H}, \mathrm{d}, J 7.0 \mathrm{~Hz}, 2-\mathrm{Me}), 1.05-1.85(8 \mathrm{H}, \mathrm{m})$, and $3.50-3.78\left(1 \mathrm{H}, w_{1 / 2} 18 \mathrm{~Hz}\right)$.

Addition of trans-2-Methyl-4-t-butylcyclohexanone with Methyl-lithium.-To a cold solution of trans-(3) $(10 \mathrm{mmol}$ in 15 $\mathrm{cm}^{3}$ ether) was added dropwise a solution of $\mathrm{MeLi}$ in ether $\left(15 \mathrm{mmol}, 1.6 \mathrm{~mol} \mathrm{dm}-3\right.$ Merck) at $0{ }^{\circ} \mathrm{C}$. After stirring for $3 \mathrm{~h}$ at $0^{\circ} \mathrm{C}$, the reaction was terminated with saturated ammonium chloride. The organic layer was washed with brine, dried $\left(\mathrm{Na}_{2} \mathrm{SO}_{4}\right)$, and concentrated to give the alcohol products cis- and trans-(6) $(4: 96)(7.5 \mathrm{mmol})$. The stereoisomers were separated by h.p.l.c. [eluant: EtOAc-hexane (1:19)]: cis-(6), $t_{\mathrm{R}}=10.4 \mathrm{~min}$, liquid, $\delta_{\mathrm{H}}\left(\mathrm{CDCl}_{3}\right) 0.85(9 \mathrm{H}, \mathrm{s}$, $\left.\mathrm{CMe}_{3}\right), 0.95(3 \mathrm{H}, \mathrm{d}, J 7.0 \mathrm{~Hz}, 2-\mathrm{Me}), 1.14(3 \mathrm{H}, \mathrm{s}, 1-\mathrm{Me})$, and $1.20-1.48(8 \mathrm{H}, \mathrm{m})$; trans $-(6), t_{\mathrm{R}}=14.5 \mathrm{~min}$, pale yellow crystal, m.p. 69-70 ${ }^{\circ} \mathrm{C}\left(\right.$ lit.. $\left.{ }^{19} 67.5^{\circ} \mathrm{C}\right), \delta_{\mathrm{H}}\left(\mathrm{CDCl}_{3}\right) 0.84\left(9 \mathrm{H}, \mathrm{s}, \mathrm{CMe}_{3}\right)$, $1.02(3 \mathrm{H}, \mathrm{d}, J 7.0 \mathrm{~Hz}, 2-\mathrm{Me}), 1.28(3 \mathrm{H}, \mathrm{s}, 1-\mathrm{Me})$, and $1.36-$ $1.59(8 \mathrm{H}, \mathrm{m})$.

\section{Acknowledgements}

Financial support from the National Science Council and the Union Chemical Laboratory are gratefully acknowledged.

\section{References}

1 (a) M. Cherest, H. Felkin, and N. Prudent, Tetrahedron Lett., 1968, 2199; (b) M. Cherest and H. Felkin, ibid., p. 2205; (c) M. Cherest, Tetrahedron, 1980, 36, 1593.

$2(a)$ N. T. Anh and O. Einstein, Tetrahedron Lett., 1976, 155; (b) N. T. Anh and O. Einstein, Nouv. J. Chim., 1977, 1, 61; (c) N. T. Anh, Top. Curr. Chem., 1980, 88, 145.

3 A. S. Cieplak, J. Am. Chem. Soc., 1981, 103, 4540.

4 W. T. Wipke and P. Gund, J. Am. Chem. Soc., 1976, 98, 8107.

5 (a) D. C. Wigfield, Tetrahedron, 1979, 35, 449; (b) B. Rickborn and W. T. Wuesthoff, J. Am. Chem. Soc., 1970, 92, 6894; (c) A. V. Kammerniskii and A. A. Akhrem, Tetrahedron, 1962, 18, 705; (d) E. L. Eliel and Y. Senda, ibid., 1970, 26, 2411.

6 W. G. Dauben, G. J. Fonken, and D. S. Noyce, J. Am. Chem. Soc., $1956,78,2579$.

7 (a) H. C. Brown and H. Deck, J. Am. Chem. Soc., 1965, 87, 5620; (b) H. C. Brown and J. Muzzio, ibid., 1966, 88, 2811.

8 (a) M. H. Rei, J. Org. Chem., 1979, 44, 2760; (b) M. H. Rei, C. L. Chen, and S. L. Liu, J. Chin. Chem. Soc. (Taipei), 1983, 30, 1;(c) M. H. Rei, J. Org. Chem., 1983, 48, 5386.

9 (a) M. H. Rei, Ph.D. Thesis, Purdue University, Indiana, 1966; (b) N. L. Allinger and C. D. Liang, J. Org. Chem., 1968, 33, 3319; (c) W. J. Hammer, Ph.D. Thesis, Purdue University, Indiana, 1967.

10 J.Sicher and T. Michy, Collect. Czech. Chem.Commun., 1967,32, 3687.

11 (a) E. J. Corey and D. Enders, Tetrahedron Lett., 1976, 3; (b) E. J. Corey and S. T. Knapp, ibid., p. 4687.

12 J. K. Whitesell and M. A. Whitesell, Synthesis, 1983, 517.

13 R. R. Fraser, J. Banville, and K. L. Dhawan, J. Am. Chem. Soc., 1978, $100,7999$.

14 H. O. House, B. A. Tefertiller, and H. D. Olmstead, J. Org. Chem., $1968,33,935$.

15 N. L. Allinger, H. M. Blatter, L. A. Feribery, and F. M. Karkowski, J. Am. Chem. Soc., 1960, 88, 2999.

16 J. M. Conia and P. Briet, Bull. Soc. Chim. Fr., 1966, 3881.

17 F. Sipos, J. Krupieka, M. Tichy, and J. Sicher, Collect. Czech. Chem. Commun., 1962, 27, 2079.

18 M. H. Rei, J. Org. Chem., 1978, 43, 2173.

19 J. Ficini and A. Maujean, Bull. Soc. Chim. Fr., 1971, 219.

Received 27th June 1988; Paper 8/02521E 